\title{
Growing evidence that radionuclide imaging identifies management strategies that improve outcome
}

\author{
Michael R. Freeman, MDa,b
}

\section{See related article, pp. 869-877}

In a policy statement published in $2005^{1}$ concerning cost effectiveness the authors concluded that 'the results consistently note significant cost savings when single photon emission computerized tomography (SPECT) is used as a gatekeeper by limiting angiography to only patients with provocable ischemia.' Significant additional studies since this statement confirm and extend the value of SPECT and other radionuclide imaging studies in directing management strategies in patients with known and suspected coronary artery disease with concurrent improvement in outcome.

In this issue of the Journal ${ }^{2}$ Al-Housini et al illustrate the power of SPECT imaging in predicting improved exercise tolerance and patient quality of life in patients undergoing elective percutaneous coronary intervention (PCI). The findings suggest that significant ischemia by SPECT and chest pain during exercise can identify the patients receiving the greatest clinical benefit with PCI. This study confirms and extends the conclusion of Hachamovitch et $\mathrm{al}^{3}$ that the extent and severity of ischemia by SPECT can determine the relative benefit of medical therapy as apposed to PCI and coronary artery bypass surgery (CABG). This approach would not only reap the greatest survival benefit for our patients but also now provide a predictor of symptomatic improvement. The use of SPECT would also result in a lower cost as suggested by the END study authors, with at least a similar outcome and possibly even a superior outcome. ${ }^{4}$

From the Division of Cardiology, ${ }^{\text {a }}$ St. Michael s Hospital, Toronto, ON, Canada; Faculty of Medicine, ${ }^{\mathrm{b}}$ University of Toronto, Toronto, ON, Canada.

Reprint requests: Michael R. Freeman, MD, Division of Cardiology, St. Michael's Hospital, 30 Bond St, Toronto, ON, Canada; freemanm@smh.toronto.on.ca.

J Nucl Cardiol 2009;16:844-5.

1071-3581/ $\$ 34.00$

Copyright (c) 2009 by the American Society of Nuclear Cardiology. doi:10.1007/s12350-009-9120-y
The study of Al-Housini et al, I believe also apply to our North American cohort of patients having coronary angiography and then being considered for PCI. In 2009, both in Canada and the United States of America, coronary angiography is commonly performed (due to enhanced access and need to know mentality) before medical therapy is optimized to make a diagnosis of coronary artery disease and assess prognosis. This study demonstrates that many patients have improvement of symptoms between the time of coronary angiography and intervention. Therefore I would suggest that in stable patients after coronary angiography we should consider the principle of the 'surgical pause' now applied in many operating rooms around the world. ${ }^{5}$ Instead of the 'occulo-stenotic refex', should we not have a pause once a coronary stenosis is identified, and ask the following:

1. Has maximal medical therapy been applied to this patient?

2. Has the extent of ischemia been evaluated?

If the answer to both questions is no, presently available data would suggest that our patients would be best served by optimizing medical therapy and evaluating the extent of ischemia. The COURAGE trial ${ }^{6}$ demonstrates that interventional therapy is not superior to optimal medical therapy in patients with coronary artery disease amenable to PCI. Death and myocardial infarction are not averted by our interventional procedures. The study of Al-Housini et al also suggests that symptomatic and functional performance improvements can be predicted by SPECT. The nuclear sub study of $\mathrm{COURAGE}^{7}$ suggests that non-high risk patients with significant ischemia by SPECT identify a cohort of CAD patients that will benefit from PCI. Patients with no or minimal ischemia do not receive clinical benefit from PCI. In addition, diabetic patients with known disease and aggressive medical therapy do not benefit from PCI as shown in the BARI 2D trial. ${ }^{8}$ An analysis of patients categorized by extent of ischemia as performed in the COURAGE sub study ${ }^{7}$ would be of interest in this important patient population with significant cardiac morbidity. Should we not be applying procedures to patients who will receive the greatest benefit, and avoid procedures that do not change outcome? 
An additional component to be considered is the risk of performing interventional procedures in patients without demonstrable ischemia or lesions that are not hemodynamically significant. The FAME trial ${ }^{9}$ demonstrated that performing PCI on lesions having a fractional flow reserve (FFR) less than 0.75 and deferring PCI if the FFR was greater than 0.75 resulted in similar symptomatic improvement with less adverse cardiac events. The value of an FFR $\leq 0.75$ by guide wire evaluation has been validated by comparison to SPECT. ${ }^{10}$ We can conclude that performing PCI on a stenosis identified at coronary angiography that is associated with normal SPECT perfusion will not avert cardiac events, improve outcome, or significantly improve functional capacity as suggested by the study of Al-Housini et al. These data may also apply to patients with low risk acute coronary syndromes. Patients with a low TIMI risk score do not benefit from early intervention and PCI. ${ }^{11}$ The conservative approach with SPECT can identify the patients who would receive the greatest benefit from intervention, both in patients with non-STEMI ${ }^{12}$ or after myocardial infarction ${ }^{13}$ and thus eliminate the need for revascularization in a significant proportion of patients.

Data from the PARR2 study ${ }^{14}$ show that management decisions concerning intervention or medical therapy can be directed in patients with severe left ventricular dysfunction. The results of FDG PET imaging identify patient management strategies that improve outcome and reduce cardiac events. Although SPECT identifies patients at high risk of a cardiac event following vascular surgery, interventions directed by SPECT have not improved outcome, at least in the short term. ${ }^{15}$ Similarly, asymptomatic patients with diabetes mellitus and no known coronary artery disease do not benefit from risk stratification with SPECT. ${ }^{16}$ We not only need to show the prognostic and risk stratification value of SPECT, but also that a meaningful impact on management strategies and outcome is demonstrated.

In conclusion, SPECT allows for management and therapeutic decision making that will improve outcome in subsets of patients with known or suspected coronary artery disease. We need to extend these findings to more diverse patient subsets by demonstrating a positive influence on management strategies.

\section{References}

1. Des Pres RD, Shaw LJ, Gillespie RL, Jaber WA, Noble GL, Soman P, et al. Cost-effectiveness of myocardial perfusion imaging: A summary of the currently available literature. J Nucl Cardiol 2005; $12: 750-9$.
2. Al-Housini MB, Hutchings F, Dalby M, et al. Does myocardial perfusion scintigraphy predict improvement in symptoms and exercise capacity following successful elective percutaneous coronary intervention? J Nucl Cardiol 2009. doi:10.1007/s12350-0099112-y.

3. Hachamovitch R, Hayes S, Freidman JD, Cohen I, Berman DS. Comparison of the short-term survival benefit associated with revascularization compared with medical therapy in patients with no prior coronary artery disease undergoing stress myocardial perfusion single photon emission computed tomography. Circulation 2003;107:2900-6.

4. Shaw LJ, Hachamovitch R, Berman DS, et al. The economic consequences of available diagnostic and prognostic strategies for the evaluation of stable angina patients: An observational assessment of the value of precatheterization ischemia. J Am Coll Cardiol 1999;33:661-9.

5. Haynes AB, Weiser TG, Berry WR, et al. A surgical safety checklist to reduce morbidity and mortality in a global population. N Engl J Med 2009;360:491-9.

6. Boden WE, O'Rourke RA, Teo KK, et al. Optimal medical therapy with or without PCI for stable coronary disease. N Engl J Med 2007;356:1503-16.

7. Shaw LJ, Berman DS, Maron DJ, Mancini GBJ, et al. Optimal medical therapy with or without PCI to reduce ischemic burden: Results from the clinical outcomes utilizing revascularization and aggressive drug evaluation (COURAGE) trial nuclear substudy. Circulation 2008;117:1283-91

8. The BARI 2D Study Group. A randomized trial of therapies for type 2 diabetes and coronary artery disease. N Engl J Med 2009;360:2503-15.

9. Tonino PAL, De Bruyne B, Pijls NH, et al. Fractional flow reserve versus angiography for guiding percutaneous coronary angiography. N Engl J Med 2009;360:213-24.

10. Pijls NH, De Bruyne B, Peels K, et al. Measurement of fractional flow reserve to assess the functional severity of coronary-artery stenoses. N Engl J Med 1996;334:1703-8.

11. Cannon CP, Weintraub WS, Demopoulos LA, et al. Comparison of early invasive and conservative strategies in patients with unstable coronary syndromes treated with the glycoprotein IIb/IIIa inhibitor tirofiban. N Engl J Med 2001;344:1879-87.

12. Marmur JD, Freeman MR, Langer A, Armstrong PW. Prognosis in medically stabilized unstable angina: Early Holter ST-segment monitoring compared with predischarge exercise thallium tomography. Ann Intern Med 1990;113:575-9.

13. Mahmarian JJ, Dakik HA, Filipchuk NG, Shaw LJ, et al. An initial strategy of intensive medical therapy is comparable to that of coronary revascularization for suppression of scintigraphic ischemia in high-risk but stable survivors of acute myocardial infarction. J Am Coll Cardiol 2006;48:2458-67.

14. Beanlands RSB, Nichol G, Huszti E, Humen D, et al. F-18Fluorodeoxyglucose positron emission tomography imagingassisted management of patients with severe left ventricular dysfunction and suspected coronary disease. J Am Coll Cardiol 2007:50:2002-12.

15. Poldermans D, Schouten O, Vidakovic R, Bax JJ, et al. A clinical randomized trial to evaluate the safety of a noninvasive approach in high-risk patients undergoing major vascular surgery: The DECREASE-V pilot study. J Am Coll Cardiol 2007;49:1763-9.

16. Young LH, Wackers FJT, Chyun DA, et al. Cardiac outcomes after screening for asymptomatic coronary artery disease in patients with type 2 diabetes: The DIAD study: A randomized controlled trial. JAMA 2009;301:1547-55. 